\title{
Blood Transfusion Increases Functional Capillary Density in the Skin of Anemic Preterm Infants
}

\author{
ORSOLYA GENZEL-BOROVICZÉNY, FRANK CHRIST, AND VERENA GLAS \\ Division of Neonatology at the Department of Gynecology and Obstetrics [O.G.-B., V.G.], \\ Ludwig-Maximilian University Munich Grosshadern, D-81366 Munich, Germany; and Clinic for \\ Anesthesiology [F.C.], Ludwig-Maximilian University Munich Grosshadern, D-81366 Munich, Germany
}

\begin{abstract}
Direct visualization of the microcirculation at the level of the skin capillaries may provide information on the quality of tissue perfusion. Orthogonal polarization spectral imaging (OPS) enables noninvasively direct observation of those blood vessels. OPS was applied to the upper arm of 13 preterm anemic infants [median (95\% confidence interval) gestational age: $26 \mathrm{wk}$ (25-26 wk); birth weight: $730 \mathrm{~g} \mathrm{(652-789} \mathrm{g})$ ] before and 2 and $24 \mathrm{~h}$ after transfusion (Tx). OPS images of skin perfusion were continuously recorded on video. Off-line quantitative data of microvascular perfusion were obtained by measuring functional capillary density, vessel diameter, red blood cell velocity, and flow. We found a significant increase in functional capillary density $2 \mathrm{~h}$ after transfusion with an additional significant rise after $24 \mathrm{~h}$ [before: 142 (134-155); $2 \mathrm{~h}$ after Tx: 185 (166-196); $24 \mathrm{~h}$ after Tx: $\left.206(185-219) \mathrm{cm} / \mathrm{cm}^{2} ; p<0.001\right)$, thus indicating improved microvascular perfusion. Vessel diameter, red blood cell
\end{abstract}

ABSTRACT

velocity, and flow did not change significantly. There were no significant changes in clinical variables, such as blood pressure, heart rate, or body temperature. Whereas conventional monitoring methods did not show any changes after transfusion, quantitative analyses of OPS images indicated improved perfusion; hence, it seems a useful monitor for assessing the response to therapies aimed to improve tissue perfusion. (Pediatr Res 56: 751-755, 2004)

$\quad$ Abbreviations
FCD, functional capillary density
MAP, mean arterial blood pressure
OPS, orthogonal polarization spectral imaging
RBC vel, red blood cell velocity
Tx, transfusion

The effect of hemodilution on capillary perfusion has been investigated extensively in the hamster skinfold model using intravital microscopy (4-7). Orthogonal polarization spectral imaging (OPS) has been developed as a noninvasive technique to investigate the human microvasculature and can be used even in small infants (8). The technology has been described in detail elsewhere (9). In brief, through the use of special optics, a virtual light source is created within the tissue and the light is absorbed by $\mathrm{Hb}$, yielding an image of the illuminated $\mathrm{Hb}$-carrying structures in negative contrast. We have previously shown that microvessel diameter, red blood cell velocity (RBC vel), and functional vessel density can be measured noninvasively by OPS in the skin of term and preterm infants (8). The aim of the study was to determine whether RBC Txs in anemic preterm infants results in an improved microvascular perfusion as indicated by a higher functional capillary density (FCD).

\section{METHODS}

Patients. The Ethics committee of the Medical Faculty of the Ludwig-Maximilians University Munich approved the study, and parental consent was sought before measurements.
Received October 6, 2003; accepted March 22, 2004.
Correspondence: Orsolya Genzel-Boroviczény, PD Dr. med., Department for Neonatology of the Children's Hospital at the Department of Gynecology and Obstetrics, Ludwig-Maximilian University Munich Innenstadt, Maistrasse 11, 80337 Munich, Germany; e-mail: genzel@med.uni-muenchen.de

Rheologics provided the Cytoscan technology used in this study. F.C. serves as a consultant to Rheologics.

DOI: 10.1203/01.PDR.0000141982.38959.10 
Decision for Tx was independent of the study and up to the discretion of the attending neonatologist. Infants usually received a $\mathrm{Tx}$ when the $\mathrm{Hb}$ was $<12 \mathrm{~g} / \mathrm{dL}$ in ventilated infants with oxygen requirement, $\mathrm{Hb}<10 \mathrm{~g} / \mathrm{dL}$ nonventilated infants but with oxygen requirement $>30 \%$, $\mathrm{Hb} 8-9 \mathrm{~g} / \mathrm{dL}$ in infants with oxygen requirement $<30 \%$ but not feeding or not gaining weight well, and any infants with $\mathrm{Hb}$ levels $<7 \mathrm{~g} / \mathrm{dL}$. Because Hb levels are measured in each blood gas, $\mathrm{Hb}$ values were more consistently available than spun hematocrit values. Infants received a Tx of 10-15 mL/kg body weight of packed cytomegalovirus-negative irradiated RBC over 4-5 h. Microcirculatory parameters were measured within $4 \mathrm{~h}$ before and 2 and $24 \mathrm{~h}$ after the Tx. Systolic, diastolic, and mean arterial blood pressure (MAP) were recorded simultaneously with the OPS measurements either continuously via an arterial line (Becton Dickinson Critical Care systems with an Ohmeda Statham Transducer, Singapore) if in place or every 5 min oscillometrically (Dinamap Critikon Vital Data Monitor, Norderstedt, Germany). Heart rate and body core temperature with a skin probe over the liver were also recorded, as was incubator temperature. Measurements were obtained in 15 infants, but two infants had to be excluded as a result of incomplete measurements. The probe was placed next to the infants' skin close to the axilla with the least possible contact to avoid pressure against the skin. Lubricating the skin with normal saline improved imaging. Measurements were started when the infants settled down and went to sleep. Sedation was not necessary. Measurements were done over 5-10 $\mathrm{min}$ to obtain as many possible sequences without movements artifacts. Data were calculated for all sequences without movement artifacts, and values were averaged. At each time point (before and 2 and $24 \mathrm{~h}$ after Tx), FCD was measured three to five times with a variance of $<10 \%$. It is not possible to measure exactly the same vessels repeatedly, but measurements before and after the Tx were always obtained on the upper arm close to the axilla.

Imaging. In OPS imaging, a virtual light source is created at a depth of $\sim 1 \mathrm{~mm}$ within the tissue through the use of special optics. The light shining back through the tissue is absorbed by $\mathrm{Hb}$, yielding an image of the illuminated vessel in negative contrast with a resolution of 1 pixel $\cong 1 \mu \mathrm{m}$. Because no fluorescent dyes are needed, it can be used in humans. The method has been validated for quantitative measurements of microcirculatory parameters in an animal model against intravital microscopy (10).

Calculation of vessel diameter, $R B C$ vel, and vessel density. Images were created using the CYTOSCAN A/R, stored on videotape and analyzed off-line. Vessel diameter, vessel density, and RBC vel were measured with the CapiScope program in as many vessels as possible per observation area (Figs. 1 and 2). To measure the diameter, a vessel is selected from the image on the video screen, and a line is placed in the vessel.

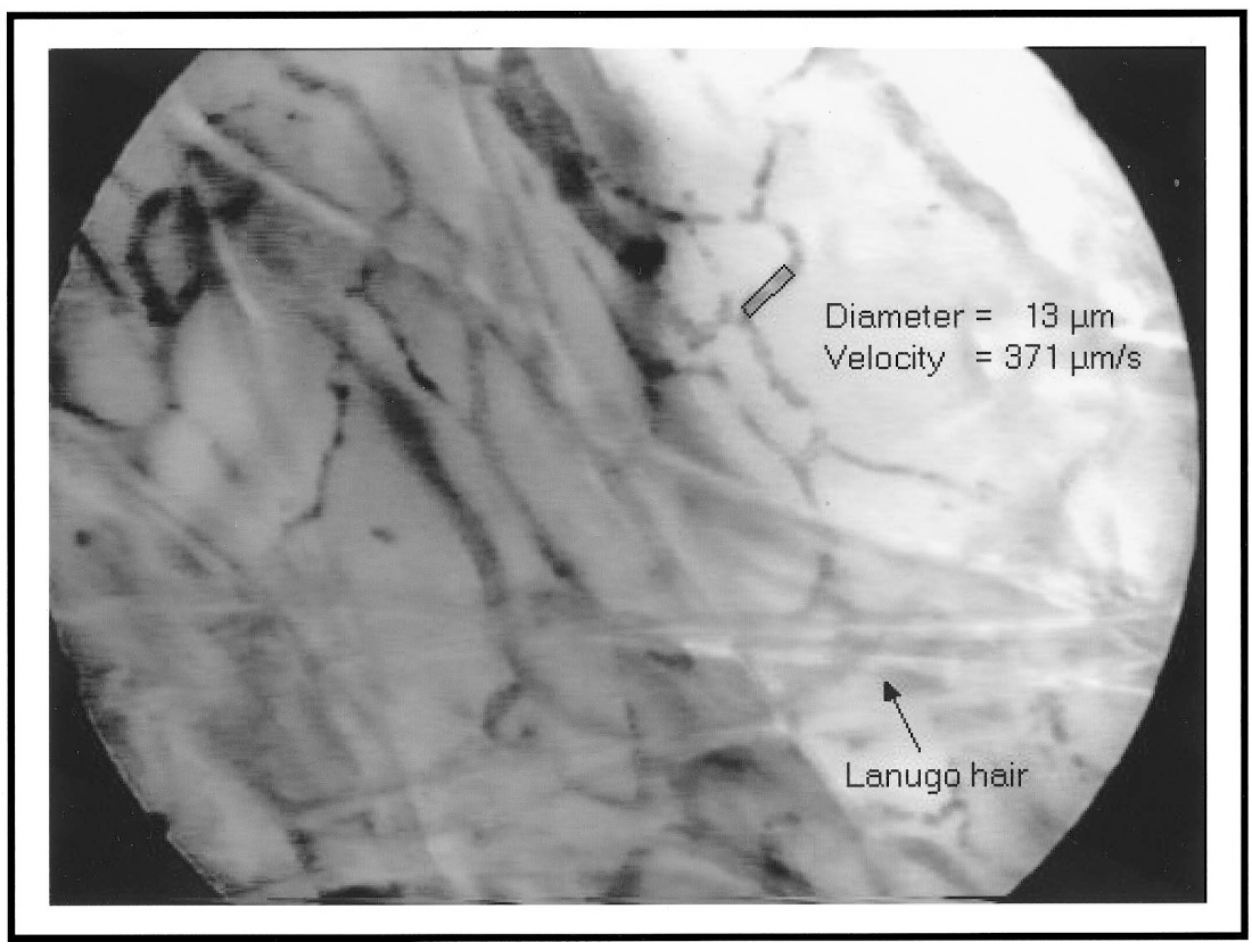

Figure 1. Measurement of vessel diameter and RBC vel. Image of the skin of a preterm infant (gestational age: 25 wk; birth weight: $685 \mathrm{~g}$ ) at day 16 and current weight of $850 \mathrm{~g}$. Vessel diameter, vessel density, and RBC vel were measured with the CapiScope program in as many vessels as possible per observation area. The $\mathrm{RBC}$ vel is measured by drawing a line along the vessel and projecting the image of the vessel onto a 1-pixel thick line. The gray profile along the line is taken for each field every 1/50th of a second. The comparison is performed by calculating the correlation coefficient for every possible shift of the previous gray level profile relative to the new profile. The shift, which produces the highest correlation, indicates the distance that the pattern traveled between the two gray level profile measurements. Because the time lapse between the two gray level profiles is known, the velocity can be calculated. For measuring the diameter, a vessel is selected from the image on the video screen and a line is placed in the vessel. The computer calculates the diameter from 1-pixel perpendicular lines placed over the whole length of the drawn line, based on the gray level change. The program then places a box over the measured vessel as depicted. The arrow points at lanugo hair, which is frequently seen in images of very premature infants. 


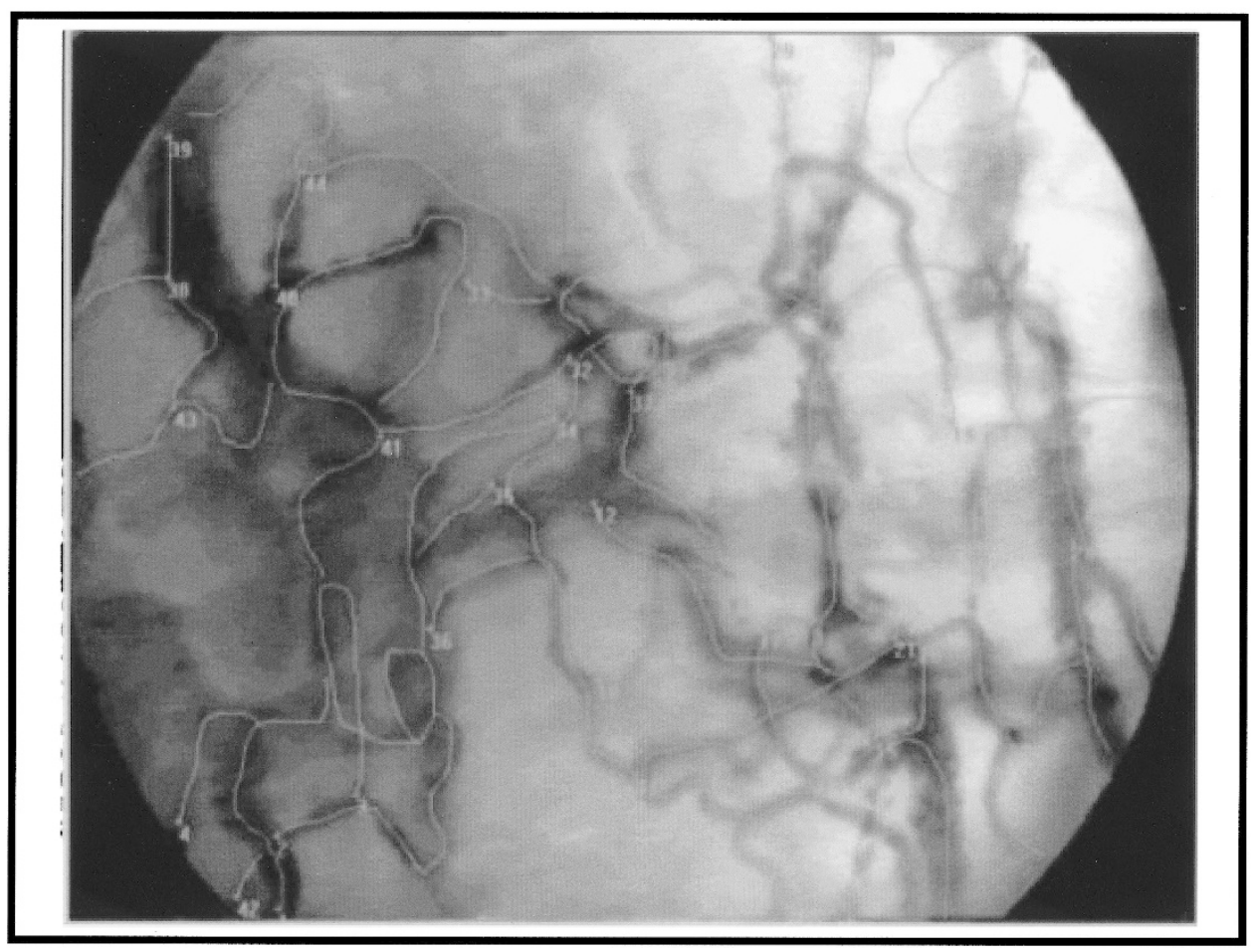

Figure 2. Measurement of FCD. Vessel density is defined as the length of RBC-perfused vessels per observation unit area and is given as $\mathrm{cm}^{\mathrm{c}} \mathrm{cm}^{2}$. Using the CapiScope Software program, the perfused vessels within the defined area are traced and the length of the marked vessels is calculated per area of observation.

The computer calculates the diameter from 1-pixel perpendicular lines placed over the whole length of the drawn line, based on the gray level change. $\mathrm{RBC}$ vel is measured using a spatial correlation technique, which requires a 10-s video sequence in which the tissue reveals little movement (for details, see Fig. 1). Vessel density is defined as the length of RBC-perfused vessels per observation unit area and is given as $\mathrm{cm} / \mathrm{cm}^{2}$ (Fig. 2). "Vessel density" refers to perfused vessel density for this article. In neonates, because of the small size of the vessel, arterioles, capillaries, and postcapillary venules cannot be distinguished clearly.

Quantitative measurement of vessel density, vessel diameter, and $\mathrm{RBC}$ vel using OPS imaging all have been validated against intravital microscopy in the hamster dorsal skinfold model and the rat liver and human sublingual tissue (9-11). Validation of the CapiScope Software program can be found at www.bridleways.uklinux.net/Videoscopy.com/index.php.

Statistics. Data are presented as median and $95 \%$ confidence interval (CI). Data were analyzed using ANOVA with a post $h o c$ test for linear trend, followed by paired $t$ test for parametric data. For correlation, the Spearman rank two-way test was applied. All calculations were done with GraphPad Prism 3.0 for Windows 95 (GraphPad Software, Inc., San Diego, CA).

\section{RESULTS}

The 13 infants [median (95\% CI) gestational age: $26 \mathrm{wk}$ (25-26 wk); birth weight: $730 \mathrm{~g}(652-789 \mathrm{~g})]$ received a Tx of $10 \mathrm{~mL}(9.3-14.2 \mathrm{~mL}$ ) packed RBCs/kg body weight at age $30 \mathrm{~d}$ (19-39 d) and current body weight of $1075 \mathrm{~g}(897-1338 \mathrm{~g})$. As expected, $\mathrm{Hb}$ values rose after $\mathrm{Tx}$, but none of the clinical variables, such as blood pressure, heart rate, or body temperature, changed significantly (Table 1). FCD increased significantly $2 \mathrm{~h}$ after the Tx (Fig. 3) with an additional significant rise after $24 \mathrm{~h}$, whereas vessel diameter, RBC vel, and flow did not change (Table 2). We found no correlation between $\mathrm{Hb}$ levels or heart rate and microcirculatory parameters. As a measure of potential oxygen transport capacity, we calculated the product of RBC flow and FCD but found no linear correlation with heart rate or $\mathrm{Hb}$ levels.

Table 1. Clinical data (median and $95 \%$ CI) before and 2 and $24 \mathrm{~h}$ after Tx

\begin{tabular}{|c|c|c|c|c|c|}
\hline & $\mathrm{Hb}(\mathrm{g} / \mathrm{dL})$ & $\begin{array}{l}\text { Heart rate } \\
\text { (beats/min) }\end{array}$ & $\begin{array}{c}\mathrm{MAP} \\
(\mathrm{mmHg})\end{array}$ & $\begin{array}{c}\text { Infant temperature } \\
\left({ }^{\circ} \mathrm{C}\right)\end{array}$ & $\begin{array}{l}\text { Incubator temperature } \\
\left({ }^{\circ} \mathrm{C}\right)\end{array}$ \\
\hline \multirow[t]{2}{*}{ Before Tx } & $8.3 * \dagger$ & 165 & 42 & 37.0 & 32.4 \\
\hline & $7.9-10.4$ & $157-174$ & $38-51$ & $36.9-37.3$ & $31.2-34.2$ \\
\hline $2 \mathrm{~h}$ after $\mathrm{Tx}$ & $9.9-12.9$ & $159-179$ & $39-51$ & $37.0-37.5$ & $30.8-33.6$ \\
\hline \multirow[t]{2}{*}{$24 \mathrm{~h}$ after Tx } & 11.8 & 164 & 39 & 37.0 & 32.1 \\
\hline & $10.8-12.9$ & $155-175$ & $35-45$ & $36.5-37.2$ & $30.6-33.6$ \\
\hline
\end{tabular}

\footnotetext{
$* p=0.04$ before $v s 2 \mathrm{~h}$ after Tx.
}

$\dagger p=0.002$ before $v s 24 \mathrm{~h}$ after Tx. 


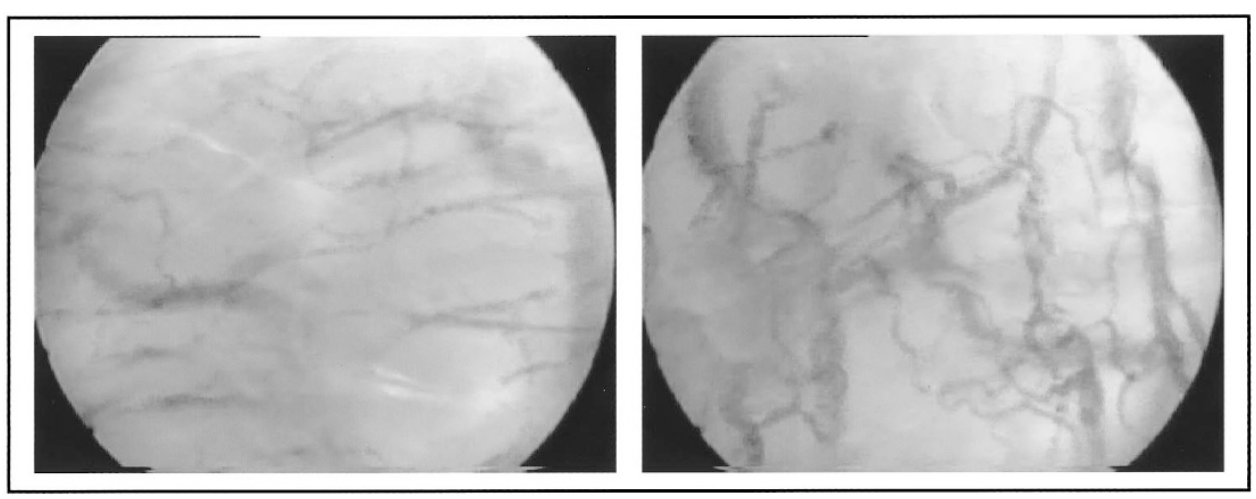

Figure 3. Image before and after Tx. The image on the left was taken $3 \mathrm{~h}$ before and the one on the right $2 \mathrm{~h}$ after Tx of packed RBCs to a 16-d-old premature infant with a gestational age of $25 \mathrm{wk}$, birth weight of $686 \mathrm{~g}$, and current body weight of $850 \mathrm{~g}$.

Table 2. Vessel diameter, density, flow, and RBC vel (median and 95\% CI) before and 2 and 24 h after Tx

\begin{tabular}{ccccc}
\hline & $\begin{array}{c}\text { Diameter } \\
(\mu \mathrm{m})\end{array}$ & RBC vel $(\mu \mathrm{m} / \mathrm{s})$ & Flow $\left(\mu \mathrm{m}^{3} / \mathrm{s}\right)$ & \multicolumn{1}{c}{ FCD $\left(\mathrm{cm}^{\prime} / \mathrm{cm}^{2}\right)$} \\
\hline Before Tx & 10.8 & 349 & 29392 & 142 \\
& $9.7-11.2$ & $336-402$ & $26625-37616$ & $134-155$ \\
2 h after Tx & 10.1 & 343 & 27797 & $185^{*}$ \\
& $9.4-10.7$ & $316-378$ & $24228-31366$ & $166-190$ \\
24 h after Tx & 10.3 & 371 & 30425 & $206^{*} \dagger$ \\
& $9.2-11.3$ & $323-392$ & $24506-36343$ & $185-219$ \\
\hline
\end{tabular}

$* p<0.0001$ vs before Tx.

$\dagger p<0.00012$ vs $24 \mathrm{~h}$ after Tx.

\section{DISCUSSION}

After birth, $\mathrm{Hb}$ concentration decreases markedly in premature infants, partially as a result of a physiologic reduction in erythrocyte number but mostly as a result of iatrogenic blood loss. However, there is no universally accepted definition of anemia requiring $\mathrm{Tx}$ in infants, because there is only a poor relationship between $\mathrm{Hb}$ level and the occurrence of pathologic symptoms, e.g. tachycardia, poor weight gain, breathing abnormalities (2). However, an effective microvascular perfusion is essential for an adequate nutritional supply, which finally guarantees appropriate organ function. In the present study, we showed for the first time that functional vessel density increases after raising $\mathrm{Hb}$ values by $2.5 \mathrm{~g} / \mathrm{dL}$, equivalent to a $30 \%$ rise. FCD is well validated and currently seems to be one of the best quantitative indicators of microvascular perfusion (12). The observed rise in FCD $2 \mathrm{~h}$ after the transfusion could be an effect of volume only rather than RBC Tx but not the further increase after $24 \mathrm{~h}$. In this context, perfusion means erythrocytes participating in nutritive exchange. This is a function of the number of erythrocytes present, the velocity of the erythrocytes, and the vessel density. FCD is currently the best parameter to assess the quality of perfusion, because we cannot evaluate the quality of nutritive exchange. Erythrocyte velocity measures only the mean speed of erythrocytes in a vessel.

In adults with a lower heart rate, the pulse variation is clearly visible in a good-quality OPS sequence. In fact, one can measure peak and lowest erythrocyte velocity and variability during the cardiac cycle. Theoretically, effects of cardiac output could probably be detected in a similar manner as used in pulse wave analysis based on photoplethysmography (13). In neonates, the vessels visualized with OPS in the skin are too small and the heart rate is too high to see these phenomena.

Relevance of measurement of skin perfusion. Cardiac output normalized to mass is much higher in the newborn than in the adult. Perfusion pressure is maintained by redistributing marginal cardiac output and oxygen supply to brain, heart, and adrenal gland. Under nonstress conditions, the skin has a high blood flow in relation to its oxygen requirement, whereas stress results in a profound vasoconstriction mainly of skin arteriovenous shunts. Whereas this holds true for all humans, this compensatory mechanism is particularly profound in neonates. Keeping this in mind, it is less surprising that most studies in premature infants have not found any significant changes in heart rate in anemic infants $(2,14)$. We would argue that in neonates, disturbance of skin perfusion can be an early sign of global tissue perfusion impairment as a result, for example, of insufficient blood volume. In this context, OPS imaging seems more suitable, because the shorter wave used in OPS (green light) allows estimations of true capillary perfusion, whereas longer wave length instrumentation such as laser Doppler instruments and infrared photoplethysmographs mainly represent vessels from a greater depth and measure a parameter more representative of total blood flow (15).

Bauer et al. (16) investigated the effects of RBC Tx on blood volume, blood pressure, and resting peripheral blood flow in the leg with strain-gauge plethysmography and blood viscosity in the first week of life. Their infants with pre-Tx hematocrits of 38\% were significantly less anemic than in our study. They found an increase in resting peripheral blood flow by $25 \%$, whereas systolic blood pressure increased by only $12 \%$. They also found that peripheral resistance decreased by $9 \%$ and 
blood viscosity increased by $21 \%$ with a decrease in vascular hindrance by $24 \%$, indicating vasodilation of limb arteries. The increase in resting peripheral blood flow and the decrease in hindrance were particularly pronounced in infants with high pre-Tx blood volume. One could speculate that the increase of blood viscosity led to recruitment of capillaries with an increase in FCD, which also might explain the increase in resting peripheral blood flow. These findings are in good agreement with our own report, because both indicate a better tissue perfusion after RBC Tx.

Studies in hemorrhagic shock show that survival is primarily determined by the maintenance of FCD and secondarily by tissue oxygenation (7). FCD is maintained as hematocrit is reduced beyond the Tx trigger by increasing plasma viscosity, which transmits systemic pressure to the capillaries and induces vasodilation through the increased shear stressdependent release of vasodilators. Consequently, the Tx trigger is also a "viscosity trigger" indicating when blood and plasma viscosity are too low. In this condition, increasing plasma viscosity is beneficial and extends the Tx trigger, reducing the use of blood Txs (7). Blood viscosity at a given hematocrit is lower in preterm infants than in term neonates and adults as a result of low plasma viscosity and low RBC aggregation, because total plasma protein levels correlate with gestational age. Consequently, the exchange of neonatal plasma with adult plasma increases blood viscosity values in the neonate to adult values. Conversely, the exchange of neonatal RBCs for adult RBCs does not affect blood viscosity. Neonatal RBCs therefore do not possess specific properties that influence blood viscosity (17). Opposite to exchanging neonatal RBCs with adult RBCs, transfusing anemic preterm infants does increase blood viscosity by $33 \%$ and also blood volume (18).

Limitations. One problem of OPS imaging for microvascular monitoring in humans is the variability of the vessels measured. Identical vessels cannot be examined over time in contrast to intravital microscopy in animal experiments (e.g. hamster skinfold chamber) or capillaroscopy of the nail fold. Hence, many more sites of interest must be evaluated to obtain statistically significant data. Movement artifacts may impair the measure velocity with the CapImage software. An additional limiting factor is the application pressure that is uncontrolled and may lead to pressure artifacts. This may result in an underestimation of the microvascular RBC vel values. Great care was undertaken to reduce these pressure artifacts by placing the probe next to the infant with basically minimal touch.

Harris et al. (19) demonstrated in the dorsal skinfold chamber of the awake Syrian golden hamster that OPS imaging technology can be used to make accurate and reproducible quantitative measurements of diameter and FCD over a wide variety of hematocrits. They found a very good agreement between measurements obtained by OPS and by standard intravital fluorescence microscopy during isovolemic hemodi- lution down to hematocrits of $25 \%$ of the initial values. In this model of isovolemic hemodilution, FCD decreased significantly at very low hematocrit values, and values of both methods were in good agreement.

\section{CONCLUSION}

We demonstrated that blood Tx in anemic neonates results in a better perfusion of skin microvessels as indicated by FCD data from OPS imaging. We suggest that OPS imaging can be used to measure microvascular perfusion in neonates and allows the assessment of the quality of tissue perfusion.

Acknowledgments. The study was part of the dissertation of V.G.

\section{REFERENCES}

1. Bohler T, Janecke A, Linderkamp O 1994 Blood transfusion in late anemia of prematurity: effect on oxygen consumption, heart rate, and weight gain in otherwise healthy infants. Infusionsther Transfusionsmed 21:376-379

2. Westkamp E, Soditt V, Adrian S, Bohnhorst B, Groneck P, Poets CF 2002 Blood transfusion in anemic infants with apnea of prematurity. Biol Neonate 82:228-232

3. Wardle SP, Garr R, Yoxall CW, Weindling AM 2002 A pilot randomised controlled trial of peripheral fractional oxygen extraction to guide blood transfusions in preterm infants. Arch Dis Child Fetal Neonatal Ed 86:F22-F27

4. Sakai H, Hara H, Tsai AG, Tsuchida E, Johnson PC, Intaglietta M 1999 Changes in resistance vessels during hemorrhagic shock and resuscitation in conscious hamster model. Am J Physiol 276:H563-H571

5. Sakai H, Takeoka S, Wettstein R, Tsai AG, Intaglietta M, Tsuchida E 2002 Systemic and microvascular responses to hemorrhagic shock and resuscitation with $\mathrm{Hb}$ vesicles. Am J Physiol 283:H1191-H1199

6. Tsai AG, Friesenecker B, McCarthy M, Sakai H, Intaglietta M 1998 Plasma viscosity regulates capillary perfusion during extreme hemodilution in hamster skinfold model. Am J Physiol 275:H2170-H2180

7. Tsai AG, Intaglietta M 2001 High viscosity plasma expanders: volume restitution fluids for lowering the transfusion trigger. Biorheology 38:229-237

8. Genzel-Boroviczény O, Stroetgen J, Harris AG, Messmer K, Christ F 2002 Orthogonal polarization spectral imaging (OPS): a novel method to measure the microcirculation in term and preterm infants transcutaneously. Pediatr Res 51:386-391

9. Groner W, Winkelman JW, Harris AG, Ince C, Bouma GJ, Messmer K, Nadeau RG 1999 Orthogonal polarization spectral imaging: a new method for study of the microcirculation. Nat Med 5:1209-1212

10. Harris AG, Sinitsina I, Messmer K 2000 Quantitative analysis of orthogonal polarization spectral images: validation in the hamster dorsal skinfold chamber. In: Messmer K (ed) Progress in Applied Microcirculation. Karger, Basel, pp 21-31

11. Langer S, Harris AG, Biberthaler P, von Dobschuetz E, Messmer K 2001 Orthogonal polarization spectral imaging as a tool for the assessment of hepatic microcirculation. A validation study. Transplantation 71:1249-1256

12. Nolte D, Zeintl H, Steinbauer M, Pickelmann S, Messmer K 1995 Functional capillary density: an indicator of tissue perfusion? Int J Microcirc Clin Exp 15:244249

13. Reuter DA, Kirchner A, Felbinger TW, Weis FC, Kilger E, Lamm P, Goetz AE 2003 Usefulness of left ventricular stroke volume variation to assess fluid responsiveness in patients with reduced cardiac function. Crit Care Med 31:1399-1404

14. Stute H, Greiner B, Linderkamp O 1995 Effect of blood transfusion on cardiorespiratory abnormalities in preterm infants. Arch Dis Child Fetal Neonatal Ed 72:F194F196

15. Hales JR, Roberts RG, Westerman RA, Stephens FR, Fawcett AA 1993 Evidence for skin microvascular compartmentalization by laser-Doppler and photoplethysmographic techniques. Int J Microcirc Clin Exp 12:99-104

16. Bauer K, Linderkamp O, Versmold HT 1993 Short-term effects of blood transfusion on blood volume and resting peripheral blood flow in preterm infants. Acta Paediatr $82: 1029-1033$

17. Linderkamp O, Versmold HT, Riegel KP, Betke K 1984 Contributions of red cells and plasma to blood viscosity in preterm and full-term infants and adults. Pediatrics 74:45-51

18. Nelle M, Hoecker C, Linderkamp O 1997 Effects of red cell transfusion on pulmonary blood flow and right ventricular systolic time intervals in neonates. Eur J Pediatr 156:553-556

19. Harris AG, Sinitsina I, Messmer K 2002 Validation of OPS imaging for microvascular measurements during isovolumic hemodilution and low hematocrits. Am J Physiol 282:H1502-H1509 